\title{
Development of stratospheric communication platforms (SCP) as a backbone to terrestrial networks
}

\author{
Dimov Stojce Ilcev \\ Space Science Centre (SSC), Durban University of Technogy (DUT), South Africa
}

\begin{abstract}
Article Info
ABSTRACT

Article history:

Received Nov 10, 2019

Revised Jan 12, 2020

Accepted Jan 20, 2020

\section{Keywords:}

Airship platform

Fixed users

Ground segment

Mobile users

SCP

VDVoIP

In this paper are introduced the new Stratospheric Communication Platforms (SCP) as cost effective airships for the future backbone of terrestrial networks for rural communications. Placing airship in position is not critical point such as launch of satellite and controlling support services in the creation of space communication technology and the most expensive phase of the total system cost. Therefore, with few cost effective remote controlled and solar powered airships can be covered any region or country including remote and rural areas with low density of population. The airship network offers better solutions than cellular radio systems, with greater speed of transmission than even optical modes, roaming will be enhanced without severe shadowing or obstacle problems and disturbances inside of buildings and service will cost less. The airship mission is more autonomous and discrete, can be integrated with current satellite and cellular systems, and will be the best solution for rural, mobile and military applications. The airship can be seen well from all positions inside coverage area, because they are overlapping the total coverage and because of elevation angle. In any circumstances mountains, buildings and trees cannot cause an obstruction that is the case in cellular networks. Thus, the current revival of interest for SCP constellations, applications and various concepts are being studied.
\end{abstract}

Copyright (C) 2020 Institute of Advanced Engineering and Science. All rights reserved.

\section{Corresponding Author:}

Dimov Stojce Ilcev,

Space Science Centre (SSC),

Durban University of Technogy (DUT), Durban, South Africa

Email: ilcev@dut.ac.za

\section{INTRODUCTION}

Despite of advances in Wireless and Terrestrial Telecommunications Technology, almost three billion of world populations living in rural locations are still without any telephone facilities. However, except already developed Fixed and Mobile Satellite Communications Networks, airships as Stratospheric Communication Platforms (SCP) or High Altitude Platforms (HAP) are the newest space technique with digital transmission technologies for fixed or mobile commercial and military applications, which include remote and rural solutions as well. These systems employs unmanned or manned and on solar or fuel energy aircraft and airships carrying payloads onboard airships with transponders (transmitters and receivers) and antennas, providing new technique known as Voice, Data and Video over IP (VDVoIP) service.

Deploying a few cost effective remote controlled and solar powered airships as a better solution, a territory can be covered of some region or country including urban, suburban and rural areas, farms and other environments with a low density of population. However, today there are developed four general telecommunications architectures, which can be used to deliver broadband wireless local loop service to consumers. Two of these architectures are Geostationary Earth Orbit (GEO) and Non-GEO satellite systems 
and the other two are terrestrial rooftop cellular-like millimeter wave repeaters and stratospheric relay platforms [1-3].

The SCP network offers better solutions than all cellular and wireless systems, with greater speed of transmission than even optical modes, roaming will be better, without shadowing problems and disturbances inside buildings and service will cost less. The SCP mission can be integrated with current satellite and cellular systems; the system is more autonomous and discrete and will be the best for military and all mobile applications. For instance, the Halo Broadband GSPS Millimetre Wavelength (MMW) Network of the Angel Company provides data densities nearly one thousand times higher than proposed satellites, presented on Table 1, while having round trip time delays appropriate for interactive broadband services.

Whereas, the delays through satellite network nodes, even through LEO satellite nodes, are too long for many interactive applications, delays are 25 or 1,000 times longer for LEO or GEO then for Halo Networks, respectively. In such a way, the Halo comparison parameters are similar to a variety of metropolitan environment spectrum used bands of the Local Multipoint Distribution Service (LMDS) band near 28 GHz.

Table 1. Comparison of data density and signal delays

\begin{tabular}{|c|c|c|c|c|}
\hline \multirow[t]{2}{*}{ Node type } & \multicolumn{2}{|c|}{ Node Data Density } & \multicolumn{2}{|c|}{ Round Trip Delay } \\
\hline & $\operatorname{Min}\left(\mathrm{Mb} / \mathrm{s} / \mathrm{km}^{2}\right)$ & $\operatorname{Max}\left(\mathrm{Mb} / \mathrm{s} / \mathrm{km}^{2}\right)$ & Min (milisec) & Min (milisec) \\
\hline LDMS & 3 & 30 & 0.003 & 0.060 \\
\hline Halo & 2 & 20 & 0.10 & 0.35 \\
\hline LEO (Broadband) & 0.002 & 0.02 & 2.50 & 7.50 \\
\hline GEO & 0.0005 & 0.02 & 200 & 240 \\
\hline
\end{tabular}

The airship projects offer cost-effective solutions by using special unmanned and non-fuel solar cell powered balloons with an estimated endurance of several months. Comparing aircraft and airship systems it is difficult now to determine which one will be better for the future applications, so here will be introduced TAO Airship Network, among other developed airship networks such as: SkyStation Global Network, SkyLARK Network, StratCon (StratoSat) Global Network, etc [2, 4-6].

\section{TAO (SkyNet) AIRSHIP NETWORK}

A Research and Development program (R\&D) on a SCP airship system is in progress since April 1998. The final goal of this project is to realize the SCP airship platform system, being capable of an acceptable long-duration station-keeping flight at a stratospheric altitude of about $20 \mathrm{~km}$. Therefore, the achievements will enable advanced wireless fixed and mobile communications, digital direct and relay broadcasting, modern broadband and multimedia transmission, high speed Internet, high-resolution observations and monitoring of the remote, rural and global environment. This advanced SkyNet SCP AIRSHIP program is recently promoted in collaboration with the Communications Research Laboratory of Japan (CRL), National Space Development Agency of Japan (NASDA) and Japan Marine Science and Technology Centre (JAMSTEC), including the Telecommunications Advancement Organization (TAO) of Japan [7, 8].

\subsection{Airship Platform System Description}

The SCP platform is an unmanned airship kept at a stratospheric altitude of about 20 to $25 \mathrm{~km}$ for broadcast and multimedia communications and Earth observation purposes. The SCP airship is equipped with corresponding communications payload, observation sensors and other necessary flight equipment. Thus, with the aim of quickly developing an SCP platform has great potential; so many research institutions in Japan began conducting the relevant research work in 1998. The SCP system is designed similar to a satellite space segment as a relay station to receive signals from ground stations using feeder links and to retransmit them to subscribers using service links.

Therefore, an airship like a satellite is carrying a payload with corresponding transponders and antenna system. At any rate, the launch of SCP into position is much simpler than putting a satellite into any orbit. After careful preparation in the hanger space, the airship is launched in 4 Ascent phases through the troposphere and Interface location point in the stratosphere and finally, it shifts to the station-keeping position. The recovery phase goes in the opposite direction, namely, the airship is slowly moved from the station-keeping position towards the Interface point and from there descends down to the ground in 4 descent phases. The airship construction has a semi-rigid hull of ellipsoidal shape, with an overall length of about $200 \mathrm{~m}$ and in diameter about $50 \mathrm{~m}$, shown in Figure 1. 


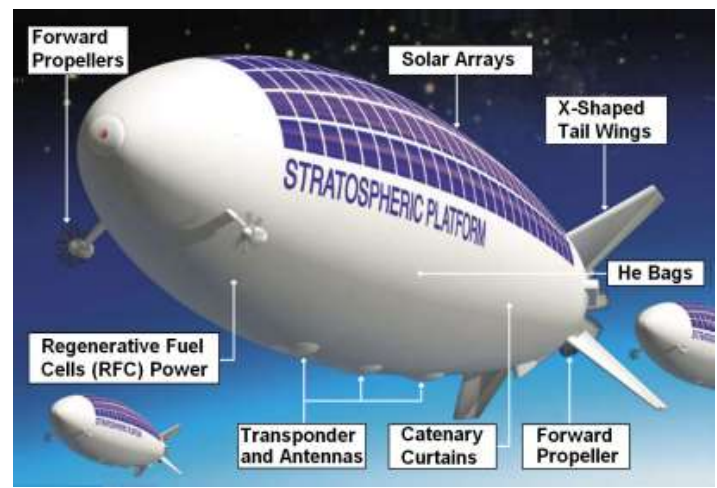

Figure 1. TAO airship with main components

Platform is composed of an air-pressurized hull for maintaining a fixed contour and internal special bags filled with the buoyant helium gas. Two air ballonets are installed inside the hull to keep the airship at a required attitude. For a load balance to the lifting force, catenary curtains are connected to the lower rigid platform's keel and are directly attached to the envelope. Propulsive propellers are mounted on both the stem and stern of the airship and tail fins are installed on the rear end of the hull. A solar photovoltaic power system of solar cells and Regenerative Fuel Cells (RFC) is provided to supply a day and night cycle of electricity for airship propulsion,

The length of any airship infrastructure in general is about $250 \mathrm{~m}$ and $60 \mathrm{~m}$ diameter. This is about 4 times as long as Jumbo jet passenger airplanes and so its weight is in total about 32 tons. However, $50 \%$ of the weight corresponds to those of structures and membrane materials. Hence, solar arrays and fuel batteries, related to the electric power subsystem, are also quite heavy. And the weight of mission equipment is supposed to be about 1 ton.

The airship platform is composed of an air-pressurized hull for maintaining a fixed contour and internal special bags filled with the buoyant helium gas. Two air ballonets are installed inside the hull to keep the airship at a required attitude. For a load balance to the lifting force, catenary curtains are connected to the lower rigid platform's keel and are directly attached to the envelope. Propulsive propellers are mounted on both the stem and stern of the airship infrastructure and tail fins are installed on the rear end of the hull. A solar photovoltaic power system of solar cells and Regenerative Fuel Cells (RFC) is provided to supply a day and night cycle of electricity for airship propulsion,

The length of an airship infrastructure in general is about $250 \mathrm{~m}$ and $60 \mathrm{~m}$ diameter. This is about 4 times as long as Jumbo jet passenger airplanes and so its weight is in total about 32 tons. However, $50 \%$ of the weight corresponds to those of structures and membrane materials. Hence, solar arrays and fuel batteries, related to the electric power subsystem, are also quite heavy. And the weight of mission equipment is supposed to be about 1 ton.

The necessary condition for an airship to float at a certain altitude is that the gravity and buoyancy forces, which are exerted on the airship, are in a state of equilibrium. When the shape and volume of the airship are supposed to be constant, unlike a balloon, the buoyant force at an altitude of $20 \mathrm{~km}$ becomes about 1/15 that at sea level. Accordingly, a buoyancy of 15 times as much is necessary for equilibrium. Therefore, in order to float a SCP in the stratosphere, it is necessary to make the weight of the airship light and to make the buoyancy as large as possible. Inside the airship there are several internal bags filled with He gas to obtain enough buoyancy [5, 9-11].

\subsection{Outline Of The Tracking and Control System}

In order to operate unmanned SCP airship safely, it is necessary to construct a tracking and control system and establish operational technique on board the platform and on the ground. Based on SCP technologies, appropriate countermeasures can be taken in time regarding observation and prediction of weather situations and monitoring of operational conditions of onboard equipment, and even regarding safety of dangerous atmospheric phenomena or abnormal performances of onboard equipment. At this point, the TAO airship system has to develop adequate TT\&C solutions on board the platform and on the ground as well. During launch airships can be affected strongly by wind, therefore, when the preliminary decision for launching or recovering of an airship is to be made, it is necessary to predict the weather data, especially wind direction and speed, in advance and estimate whether.

1) The airship deviates from the area, within which the tracking and control system works effectively. 
2) The launch of SCP airship or recovery can be conducted safely.

Based on this proper estimation, a final decision to launch or recover is made safely. After the last checks, the airship is released. It starts to ascend due to the effects of the buoyancy. Near the tropopause, which is the layer between the troposphere and stratosphere, it continues to ascend, being drifted by the jet stream. Finally, the airship arrives in transfer position at an altitude of about $20 \mathrm{~km}$. After this operation, the airship is moved to the geo station-keeping position and the mission operation is started. Once an airship is launched, it can be used for a maximum of three years. Namely, an airship is periodically, about every three years, recovered and the He gas and onboard equipment condition is checked. Moreover, after these routine checks, it is launched again. The life of an airship is supposed to be more ten and even twenty years.

Owing to its proximity to Earth, the two-way time delay for traffic to and from platform would be negligible compared with satellite links. The use of microwave (MW)-powered amplifiers for airships may deploy a large ground antenna system to SCP stations. The power antenna beam would be accurately focused onto the airplane. A rectifying antenna, mounted on the lower surfaces of platform, would receive and convert MW power to Direct Current (DC) power. The DC power would be used to drive electric motors on the SCP airship for propulsion, to power the payload and control systems and to charge standby energy storage units. If a fixed transmit power is considered, a large rain fade margin would be required, which could cause interference to other services when operating in clear sky. Therefore, an automatic power control would be very efficient in reducing the probability of interference. This automatic power control system can be implemented by using an airship with variable gain, which uses a variable attenuator located inside the airship platform $[5,12,13]$.

\subsection{Spectrum Regulations}

Radio communication is the primary method of remote command and control of airship platforms. Seamless operation of unmanned and manned aircraft or airship in the existing mobile traffic control architecture requires high-availability communication links between the SCP airship stations and the Ground Control Station (GCS). Thus, to date, International Telecommunication Union-Radiocommunications (ITU-R has partially examined the radio communication needs of civil SCP airship stations in different recommendations on SCP and World Radiocommunication Conferences-07 (WRC-07) resolutions [WRC-734].

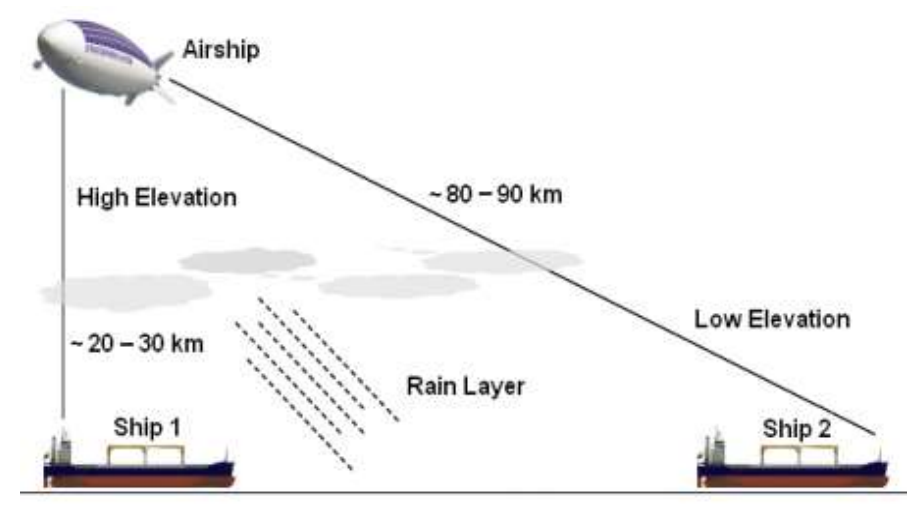

Figure 2. Impact of lower elevation angle on path loss

Nevertheless, the issue has not yet been fully addressed, with a need to promote ITU-R studies between 2007 and 2011 in order to seek more comprehensive ITU-R Spectrum requirements and possible spectrum allocations to support remotely controlled air operations as well as payload radio communication applications of SCP stations based on the results of ITU-R studies need to be addressed in WRC-11. Some of the issues that need to be resolved include.

1) Future technologies and performance expectations for civil UAS that require the use of spectrum to support the transfer of SCP airship status information to its control station, the transfer of flight commands to the airships from its control station, and the real-time relay of mobile traffic control instructions to and from the platform operator.

2) Co-existence of terrestrial and satellite communications.

3) International spectrum harmonization $[2,5,14]$. 


\subsection{System Availability and Efficiency}

Network availability is defined as the percentage of time for which services are not affected by network outage, namely due to shadowing or blocking. In wireless communications systems, environmental considerations, such as structure, rain, terrain, and so on, have the greatest effect on network availability. Another factor that impacts network availability is the loss margin. At the frequencies for which airships have been allocated, and especially those in the millimeter-wave part of the spectrum (above $27 \mathrm{GHz}$ for airships), link budgets do not allow for very much loss margin. Because of the importance of mitigating loss, gain is therefore an essential parameter that needs to be accounted for in the link budget, particularly so at low elevation angles at $15^{\circ}$, where the direct path between the airships and the ground station is longer and so the path loss becomes larger than in the case of higher elevation angles at 90 o. The impact of a lower elevation angle on path loss is illustrated in the example in Figure 2.

Assuming an operating frequency of $28 \mathrm{GHz}$, an airship stratospheric platform at about 20 to $30 \mathrm{~km}$ above the Earth is viewed by a user on the ground from two elevation angles at $90^{\circ}$ (Ship 1) and at $15^{\circ}$ (Ship 2). While the direct path between Ship 1 and the airship platform is 20 to $30 \mathrm{~km}$ and 80 to $90 \mathrm{~km}$ between Ship 2 and the airship platform, resulting in two different path losses, $152 \mathrm{~dB}$ and $164 \mathrm{~dB}$ respectively. In such a way, using practical sample of $21 \mathrm{~km}$ distance between airship and Ship 1 and $81 \mathrm{~km}$ between airship and Ship 2, the difference of $12 \mathrm{~dB}$ represents 16 times more power, and this is high enough that it may not be accommodated for in a tight airship platform link budget presented in the following relations.

$$
\begin{aligned}
& \mathrm{L} 90=20 \log [4 \pi(21000)(28 \times 109) / 3 \times 108]=148 \mathrm{~dB} \\
& \mathrm{~L} 15=20 \log [4 \pi(81000)(28 \times 109) / 3 \times 108]=160 \mathrm{~dB}
\end{aligned}
$$

Power gain is also significant to the ground antenna as it determines the data rates available to the customer on the ground. At this point, high-gain communication antennas are necessary at millimeter-wave frequencies in order to overcome rain fades. Using rain statistics and link budget calculations, and assuming a downlink of $28 \mathrm{GHz}$, a channel bandwidth of $12.5 \mathrm{MHz}$, and a cell diameter of $6 \mathrm{~km}$. Moreover, Table 2 outlines a few scenarios of airship system availabilities with the link margin required to overcome rain fades $[1,5,15]$.

Table 2. Example of downlink data rates at $28 \mathrm{GHz}$ for various types of users

\begin{tabular}{lll}
\hline Ground Terminal Type & Data Rate $(\mathrm{Mb} / \mathrm{s})$ & Availability \\
\hline High Portable (100\% Antenna) & 2 & 99 \\
Fixed (28\% Antenna) & 4 & 99.9 \\
& 10 & 99 \\
Steered (2\% Antenna) & 12 & 99.9 \\
& 40 & 99 \\
\hline
\end{tabular}

\subsection{High Antenna Directivity}

The values of high antenna directivity is the intensity with which the communication antenna radiates in its preferred direction, is needed to minimize co-channel interference and maximize Signal-to-Noise Ratio (SNR) so as to direct the wanted signal to users within the coverage area. Cellular, mobile and other applications are dependent on the high directivity of antenna beams to illuminate a specified cell coverage region, outside of which will result in interference in contiguous cells and the decrease of Carrier-to-Interference Ratio (CIR). The CIR can also be adversely affected by rain scattering and attenuation, which as already mentioned are more critical at millimeter-wave frequencies, resulting in sub-optimal system performance. In fact, it has been proposed that this can be solved by using tighter antenna bandwidths and sidelobes. The antenna directivity is the ratio of the maximum radiation intensity to the average radiation intensity. The directivity and the power gain are then related by the following equation.

$$
\mathrm{G}(\theta, \phi)=\theta \mathrm{D}(\theta, \phi)
$$

Where value of $\mathrm{G}=$ gain of antenna, $\mathrm{e}=$ efficiency, $\theta=$ angle between the considered direction and the one in which maximum power is radiated, known as boresight, $\phi=$ phase, and $\mathrm{D}=$ directivity. From its definition, the directivity $(\mathrm{D})$ is given by.

$$
\mathrm{D}=(4 \pi \mathrm{xUm} / \mathrm{W})=4 \pi / \Omega \mathrm{A}
$$


Where value of $\mathrm{Um}$ is the maximum radiation intensity [W/rad2], $\mathrm{W}$ is the total power radiated $\mathrm{W}$ and $\Omega \mathrm{A}$ is the beam solid angle [rad2].

Given the tight requirements imposed by link budgets, all three parameters must be considered when designing the system. For instance, this relationship indicates that high directivity with poor efficiency could still result in loss if power is poorly radiated, and this is the case of some airships communication antennas. Therefore, the ideal gain of antenna can be defined with an isotropic (hypothetical) antenna, which has an isotropic radiation pattern $\mathrm{E}(\theta, \phi)$, without any losses and therefore radiates power in all directions in uniform intensities $[5,16,17]$.

\subsection{Cell Plannig}

Cell planning is used to optimize coverage, make better usage of the frequency and enhance signal quality. The airship platform, terrestrial and satellite systems share allocated frequency bands so interference analysis is critical to cell planning, which have different considerations for airship than for terrestrial systems. The airship-based systems are affected by co-channel interference, which determines the carrier-to-interference ratio CIR distribution on the ground, but are unaffected by propagation characteristics due to terrain characteristics. To minimize interference, antenna specifications are of paramount importance to ensure optimum antenna beams that will illuminate its corresponding cell with uniform power across the airship platforms cell and no power falling outside of it. For instance, aperture types have better radiation characteristics. In such a way, antenna selection should also consider the production of beams that have very low sidelobes and a steep roll-off in the main lobe, and directivity that is either too high resulting in excessive power roll-off at the edge or too low resulting in excessive power falling outside of the cell $[1,18]$.

\subsection{Call Admission Control}

Call Admission Control (CAC) schemes are used to controls the number of users within the service area. There are many CAC schemes for SCP airships have been proposed. According to the scheme presented in [14] the call will be admitted if the downlinks transmit power of all mobiles was found so as to satisfy the SNR requirements at available power levels. To calculate the grade of service $(\mathrm{GoS})$ the following algorithm is used.

$$
\mathrm{GoS}=\mathrm{Pb}+10 \mathrm{Pd}
$$

Where $\mathrm{Pb}$ is the blocking probability, $\mathrm{Pd}$ is the probability of having a drop call.

Another example of call admission control can be where two centralized schemes for an airship platform carrying a Wideband-Code Division Multiple Access (W-CDMA) payload, one with priority queuing and the other with random service. Thus, taking into account the reverse link interference for a mobile terminal, interference is created by the power received from other mobiles within its service area and from mobiles located at other cells. At this point, in order to ensure that all the service classes maintain their respective QoS, a required Signal-to-Interference Ratio (SIR) level should be satisfied, as previously stated. However, this imposes a constraint on the maximum total received power at an arbitrary base station and these schemes were evaluated in terms of $\mathrm{Pb}, \mathrm{Pd}$ and $\mathrm{GoS}$.

Some wireless technologies will comprise inter-working networks and airship platforms definitely constitute an attractive solution for the provision of broadband multimedia services. Besides, on the basis that multi-technology and multi-mode user terminals will become available in the next future, novel CAC algorithms are essential, since they will decide on the serving network according to application and QoS requirements, traffic load, price, etc. A seamless soft handover between the architectures mentioned above also needs to be developed.

Therefore, CAC access scheme is necessary to ensure each mobile's QoS requirements, by regulating the volume of traffic or mobiles within a service area so that the value of the SIR level is always above a predefined limit. If incoming traffic is received beyond this limit, the interference level will be increased while the SIR will fall below its predetermined threshold, and handover is initiated often by system operators.

The CAC control centre is in charge of all the real-time network control resources, which is similar to a satellite operating centre, which operates $24 \mathrm{~h}$ a day. This control centre includes user authentication, call admission, management of the radio-electric resources, traffic management and data compilation for invoicing and accounting. The remote control centre in the ground station performs all non-real-time network management tasks, including those of all distant head ground stations. It is, essentially, the networks operating centre. The circuits of the configuration control centre are in charge of monitoring, telemetry and instructions to the platforms and the payload $[2,14,19,20]$. 


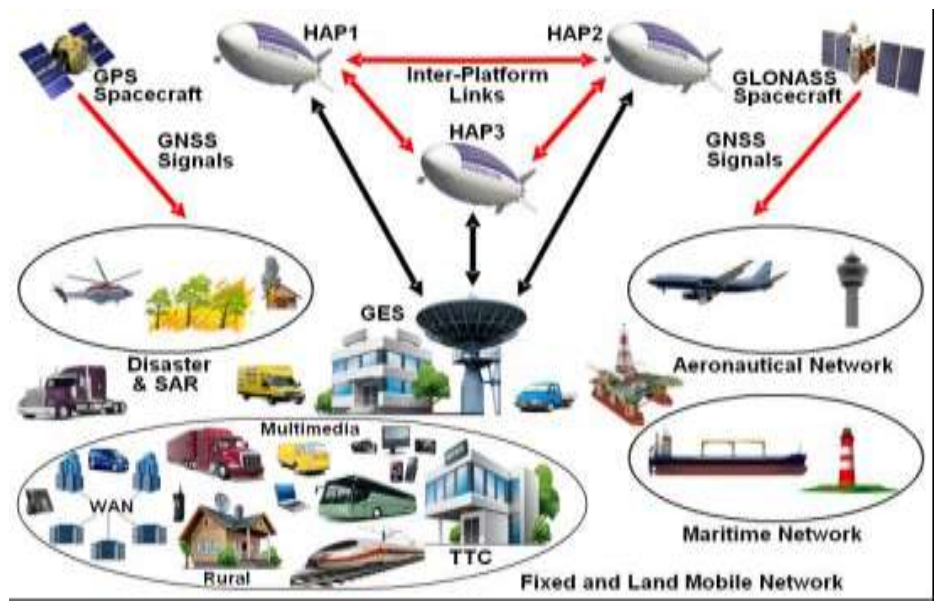

Figure 3. Fixed and mobile communication network via airships

\section{AIRSHIP NETWORK COVERAGE}

The main question of the future system is how many airship platforms are necessary to cover all particular territory or country and can this system be global? In fact, a 15 Stratospheric Platform arrangement is necessary to cover all the territory of the Japanese islands for communications and broadcasting systems, under the condition of $22 \mathrm{~km}$ airship altitude with a minimum elevation angle of $10^{\circ}$. A single airship can cover a certain service area independently, so that, for example, the service can be started from an area with a large density of population with the number gradually increased. This possibility of flexible business development is one of the merits of SCP systems.

The service area of SCP network enables that one airship can cover generally depends on certain available numbers of ground Transmitter (Tx), Receiver (Rx), two-way direction antennas, methods of modulation and transmission and many other factors. Otherwise, the final intention of this project is to offer services to other regions and certain countries and if economical and technical evaluations are correct, it will provide global coverage. The concept of the system is very advanced in comparison with similar projects and has almost no disadvantages [2,21].

\section{GROUND SEGMENT FEATURES}

The CSP system is designed for fixed and mobile multimedia two-way communications system. The ground segment consists of Ground Earth Stations (GES) or Gateways and fixed, semi fixed and mobile communication terminals, with onboard corresponding auto tracking and focusing antenna systems for all applications, respectively. A complete inter-platform links, fixed and mobile broadband multimedia service program with all applications is presented in Figure 3. Onboard the airship there is mission equipment to provide Multimedia and Broadcasting for Fixed and Mobile communications including an Earth observation and Disaster Monitoring System. So, airship is expected to have the following features.

1) Broadband communications and broadcasting are possible with small-sized and very low-power SCP airship terminals, because of much shorter propagation distances compared with satellite systems.

2) High-quality, reliable and very cost-effective communications and broadcasting systems via SCP airships are possible with a smaller number of ground stations, due to significantly better Line-of-Sight (LOS) conditions, less wave-blocking and multi-path effects compared with existing ground systems.

Meanwhile, compared with satellite systems, the propagation distance is shorter by about 1/1800. Consequently, as Electro Magnetic (EM) radiation propagation losses and delay distortions become much smaller, broadband communications and broadcasting are possible with smaller sized and lower power fixed and mobile terminals.

3) By establishing interplatform links, high-speed communications and broadcasting networks, comparable to optical fiber systems will be possible including novel communications.

4) Optimum communication configurations links are possible owing to the flexible operations of airship SCP systems, which can enable expansion to a world communications system.

Digital TV Broadcasting by SCP will use about 15 CSP to cover all of Japan, where over 10,000 stations are necessary at present. This system will be an advanced communications complement to terrestrial systems at 
very low cost. Thus, access to for wireless communications systems will be more cost-effective than optical fiber systems.

The TAO SCP airship system will enable much advanced and better communications for developing countries and will promote spreading diffusion, broadcasting content, newsgathering and backbone to terrestrial telecommunication networks. Emergency communications systems will retain communications links in an emergency by moving into position over the area. Various remote-sensing services will be available for radio wave observations, aerial photographs, meteorological observations and so on. In fact, fixed ground terminals can be a self-contained portable or office PC configuration with modem, or as an integrated part of an advanced LAN or WAN, laptop, video, fixed telephone set in office or public and mobile or cellular phone equipment. Mobile systems for Communication, Navigation and Surveillance (CNS) will offer maritime, land, aeronautical and personal applications including GNSS access. At this point, mobile user terminals can be PC/laptop portable or fixed configurations interfaced to the SCP transceiver with adequate antennas or self-contained mobile or portable/in vehicle transceiver units with mobile auto tracking antenna and personal handheld terminals with built-in antenna.

In Figure 4 is shown the prototype of fixed and mobile SCP equipment and their services. Maritime SCP equipment and system will provide two-way commercial, distress, emergency and safety communications for ships, fishing and other boats integrated with GEO and GNSS systems. In the framework of this service, there will be additional activities like buoy and lighthouse control, marine pollution, investigation, warnings and Search and Research (SAR) missions. Land mobile equipment and systems will provide services for all kinds of vehicles like trains, buses, trucks and cars, including personal mobile units, cellular service and emergency communications for natural disasters, which can be enhanced with equipment for tracking and navigation facilities. The SCP has to substitute or integrate current cellular systems.

Aeronautical mobile equipment and systems will provide commercial, safety and distress service for all kinds of aircraft integrated with GEO, GPS and other Global Navigation Satellite Systems (GNSS) to provide CNS service. The broadcasting system using the SCP airship constellation will provide: 1) digital broadcasting; 2) complementary terrestrial digital broadcasting to fixed and mobile SCP stations; 3 ) terrestrial rebroadcasting programs; 4) relay broadcasting of HDTV including radio programs; 5) movable broadcasting on demand, using mobile equipped stations; 6) broadcasting for limited suburban regions, isolated islands, rural and remote places; 7) field pickup from the SCP; and 8) emergency news and observations [5, 22, 23].

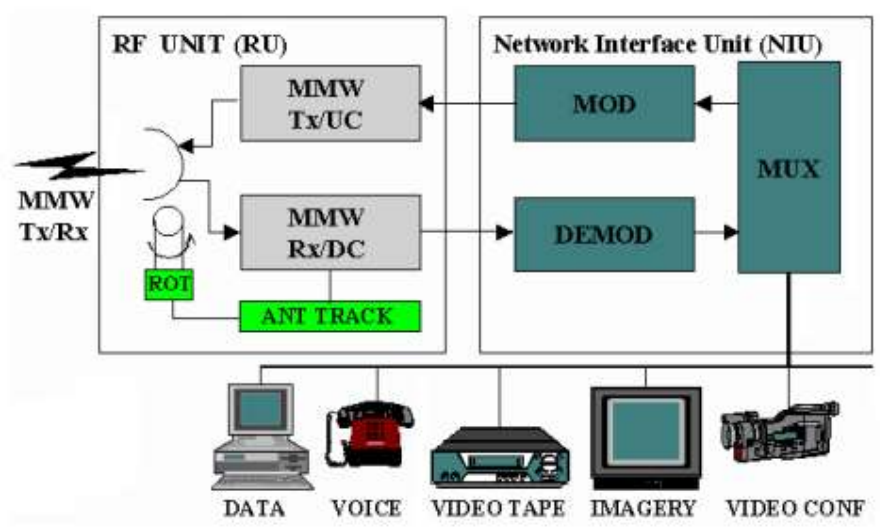

Figure 4. Functional block diagram of airships subscriber equipment

\section{ELECTRONIC POWER AND MOTION OF AIRSHIP}

Unmanned SCP airships are maintained in the stratospheric zone constantly at an altitude of 20 to 25 $\mathrm{km}$ above commercial flights, where the winds, flow and other meteorological conditions are calm. The mean temperature is -60 to $-50^{\circ} \mathrm{C}$ and the atmospheric pressure is about $50 \mathrm{hPa}$. The altitude of $20 \mathrm{~km}$ is about 60 times higher than the Tokyo TV Tower, so better Lines-of-Sight (LoS) are obtained. However, multi-path effects will be significantly reduced in most areas because of higher elevation angles. There are no clouds in the stratosphere, so perfectly clean solar energy can be used without atmospheric pollution.

The concept of SCP airship launch and recovery features an upwind orientation of the airship heading, assuming limited wind speed at the ground surface for takeoff and landing. In additional, for ascents and descents, the airship heading and position should be kept always in an upwind direction, while non-powered 
flights should require only the buoyant lift into the jet stream. Stratospheric platforms do not use any fuel for motion, so the only necessary energy is supplied by electric power, obtained from solar cells. The wide part in the graphic of an airship's topside is the solar cell array. Solar cells can supply clean energy without $\mathrm{CO}^{2}$ gas generation, so that it is said to be kind to the Earth and is an ideal form of energy. Only electric power of about $200 \mathrm{~kW}$ is necessary for stratospheric platforms and it is used for the following reasons.

1) To rotate propulsive propellers and supply electric power to the various positioning and attitude controlling systems for station keeping.

2) To operate the on-board payload for mission of communication, broadband and Earth observation systems are necessary about $10 \mathrm{~kW}$.

3) To charge the fuel battery in the daytime and to use it at night, when no solar electric power is obtained. The position of an airship is as stationary same as a GEO satellite. Namely, as the airship is used as a platform for communications and broadcasting, it is necessary for it to be almost stationary, like a broadcasting satellite. Meanwhile, the position of the airship cannot be permanently stationary because of affects from different parameters, which have an influence on the moving range. At this point, it is necessary to provide permanent control of platform moving and when necessary to correct its position using station-keeping correction motors with forward and rear propellers.

Consequently, as the maximum wind speed is sometimes over $20 \mathrm{~m} / \mathrm{sec}$ at altitudes of 20 to $22 \mathrm{~km}$, it will be very difficult for the airship to be controlled as strictly as geostationary satellites. The moving range of a stratospheric platform is very slow and in such a way requirements of station keeping are within a radius of $1 \mathrm{~km}$ in the horizontal plane and $+/-1 \mathrm{~km}$ in the perpendicular direction and under this condition the design and fabrication of onboard equipment is considered. A receiving antenna on the ground is set with the bore sight (the axis of the antenna beam) to the airship, so that the maximum receiving power can be obtained. If the position of the airship is changed, the receiving power decreases.

The airship SCP station is controlled so as to keep the position as stable as possible. For example, for a $20 \mathrm{~cm}$ diameter antenna, a position change of $600 \mathrm{~m}$ induces $3 \mathrm{~dB}$ or $50 \%$ power loss. This tendency depends upon the communication antenna size and operational frequency. In this instance, the larger an antenna radius or the higher the frequency, the receiving power becomes less and vice versa. Accordingly, to satisfactorily solve these receiving problems, an automatically pointing corresponding adjustable antenna is being considered and in this way, it is necessary to develop a low-cost and small-sized antenna with automatic tracking system $[5,24,25]$.

\section{CONCLUSION}

There are several unique attributes that allow SCP constellation, either aircraft or airships, to offer low-cost broad array service. The SCP infrastructures do not require launch vehicles, they can move under their own power throughout the world or remain stationary, and they can be brought easily down to Earth surface after several months of mission, refurbished and re-deployed without service interruption. With only several SCP airships units is possible to provide regional or local countrywide coverage, while with infrastructure of interplatform optical links between nearby SCP airships is possible to enlarge coverage and enhance service. Every SCP is independent and autonomous for dedicated service area, so once a platform is in right position, it can immediately begin delivering service to its coverage area without the need to deploy a global constellation of platforms to operate. This attribute is very important for rural, mobile and military applications.

The altitude enables the SCP system to provide a higher frequency reuse between nearby platform and higher capacity than other wireless systems. Located in the stratosphere 20 to $25 \mathrm{~km}$ above the Earth, each SCP is acting as the very low orbiting satellite, providing high density, capacity and speed service with low power requirements and no latency to entire urban and rural areas. The inexpensive SCP and Gateway stations make it the lowest cost wireless infrastructure per all subscribers conceived to date. The flexibility, reliability, enhanced capabilities and its low-cost will revolutionize telecommunications.

Joint venture private companies, government and other authorities located in each country will control the SCP configurations serving their region to ensure the best service offerings tailored to the local market. All types of SCP missions are environmentally very friendly, because most of them are powered by solar technology and non-polluting fuel cells. The SCP airship provides all subscribers with short paths through the space and unobstructed free of shadowing LOS. With very small antenna, transceivers and low power requirements, the SCP system allows for a wide variety of fixed, mobile and portable user terminals to meet almost any service need including distress, commercial and military applications. 


\section{REFERENCES}

[1] Zavala A., "High-Altitude Platforms for Wireless Communications," John Wiley, Chichester, 2008.

[2] Grace D. \& Mohorcic M, "Broadband Communications via High Altitude Platforms," Wiley, Chichester, 2011.

[3] Ilcev D. S. "Global Mobile Communication, Navigation and Surveillance (CNS)," Manual, DUT, Durban 2014.

[4] Ilcev D. S., "Stratospheric Communication Platforms (SCP) as an Alternative for Space Program," AEAT Journal, Emerald, Bingley, 2011.

[5] Ilcev D. S., "Global Mobile Satellite Communications for Maritime, Land and Aeronautical Applications," Volume 1 \& 2, Springer, Boston, 2016.

[6] Ilcev D.S., "Communication Stratospheric Platforms," Journal of the Institute of Telecommunications Professionals," Sunbury on Thames, 2010.

[7] Shimamoto I. S., "The Channel Characterization and Performance Evaluation of Mobile Communication Employing Stratospheric Platforms", IEEE Communication Magazine, 2005.

[8] TAO, "Stratospheric Platforms," Introduction, Tokyo, 2006.

[9] Tozer T.C. and Others, "High-altitude Platforms for Wireless Communications," Electronics and Communication Engineering Journal, 2001.

[10] Antonini M. \& Others, "Stratospheric Relay: Potentialities of New Satellite-high Altitude Platforms Integrated Scenarios," IEEEAC, 2003.

[11] Thornton J.\& Grace D., "Optimizing an array of antennas for cellular coverage from a High Altitude Platform," IEEE Transaction, Wireless Communications, New York, 2003.

[12] Tafazolli R., \& Others, "Centralized Total Received Power Based Call Admission Control for High Altitude Platform Station UMTS, ” 13th IEEE International Symposium on PIMRC, Lisbon, 2002.

[13] Tafazolli R., \& Others, "Centralized downlink call admission control for high altitudes platform station UMTS with onboard power resource sharing," 56th IEEE VTC, Vancouver, 2002.

[14] ITU, "Technical and operational characteristics of gateway links in the fixed service using high altitude platform stations in the band 5 850-7 075 MHz to be used in sharing studies," ITU-R Publication, Geneva, 2011.

[15] Petit D. \& Others, Spectrum for UAS, "Status of WRC-2007 preparation and proposal for a new agenda item for WRC-2011," Proceedings of the European Test and Telemetry Conference, ETTC.07, Toulouse, 2007.

[16] Horwath J. \& Other, "Broadband Backhaul Communication for Stratospheric Platforms: the Stratospheric Optical Payload Experiment (STROPEX)," Free-Space Laser Communications VI, 6304, San Diego, 2006.

[17] Miura R. and Others, "Experiments on IMT-2000 Using Unmanned Solar Powered Aircraft at an Altitude of $20 \mathrm{~km}$," IEEE Transactions on Vehicular Technology, Vol. 54, No. 4, 2005.

[18] Struzak, R., "HAP-High Altitude Platforms," CTP-ITU-URSI School on Wireless Networking for Development, ICTP, Trieste, Italy, 2007

[19] Antonini M., Cianca E., De Luise A., Pratesi M., \& Ruggieri M., "Stratospheric Relay: Potentialities of New Satellite high Altitude Platforms Integrated Scenarios", IEEEAC, 2003.

[20] Lee C.Y.W., "Mobile communications engineering", McGraw-Hill, London, 1982.

[21] Mohammed A., \& Yang Z., "Broadband Communications and Applications from High Altitude Platforms", ACEEE International Journal on Communication, 2010.

[22] Walker J., "Mobile information systems", Artech House, Boston - London, 1990.

[23] Khoury G.A. \& J. David Gillett J.D., "Airship Technology", Cambridge University Press, London, UK, 2000.

[24] Sao1 J. K., Patel P., \& Mahant T. B., "A Brief Overview on High Altitude Platforms (HAP)", International Journal of Advance Research in Science and Engineering (IJARSE), 2016.

[25] Karapantazis S., \& Pavlidou F., "Broadband Communications via High Altitude Platforms (HAP): A Survey", IEEE Communications Surveys \& Tutorials, 2005.

\section{BIOGRAPHIES OF AUTHORS}

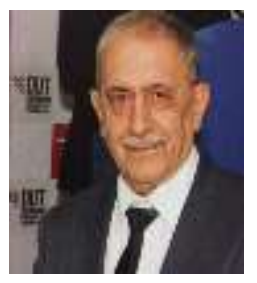

Prof. Ilcev is research leader of the Space Science Centre (SSC) for research and postgraduate studies at Durban University of Technology (DUT). He has three BSc degrees in Radio, Nautical Science and Maritime Electronics and Communications. He got MSc and $\mathrm{PhD}$ in Mobile Satellite Communications and Navigation as well. Prof. Ilcev also holds the certificates for Radio operator 1st class (Morse), for GMDSS 1st class Radio Electronic Operator and Maintainer and for Master Mariner without Limitations. He is author of several books in mobile Radio and Satellite CNS, DVBRCS, Satellite Asset Tracking (SAT), Stratospheric Platform Systems (SCP) for maritime, land (road and railways) and aeronautical applications. 